\title{
Article \\ Immobilization of (Aqueous) Cations in Low pH M-S-H Cement
}

\author{
Maximilian R. Marsiske ${ }^{1}$, Christian Debus ${ }^{1}$, Fulvio Di Lorenzo ${ }^{2}{ }^{\circ}$, Ellina Bernard ${ }^{3}{ }^{\circledR}$, Sergey V. Churakov ${ }^{2,4}$ and \\ Cristina Ruiz-Agudo ${ }^{1, *}$ \\ 1 Department of Physical Chemistry, University of Konstanz, 78457 Konstanz, Germany; \\ maximilian.marsiske@uni-konstanz.de (M.R.M.); christian.debus@uni-konstanz.de (C.D.) \\ 2 Institute of Geological Sciences, University of Bern, 3012 Bern, Switzerland; \\ fulvio.dilorenzo@geo.unibe.ch (F.D.L.); sergey.churakov@geo.unibe.ch (S.V.C.) \\ 3 Department of Civil and Environmental Engineering, Imperial College London, South Kensington, \\ Skempton Building, London SW7 2AZ, UK; e.bernard@imperial.ac.uk \\ 4 Laboratory for Waste Management, Paul Scherrer Institute, 5232 Villigen, Switzerland \\ * Correspondence: cristina.ruiz-agudo@uni-konstanz.de; Tel.: +49-7531-88-4808
}

Citation: Marsiske, M.R.; Debus, C.; Di Lorenzo, F.; Bernard, E.; Churakov, S.V.; Ruiz-Agudo, C. Immobilization of (Aqueous) Cations in Low pH M-S-H Cement. Appl. Sci. 2021, 11, 2968. https://doi.org/10.3390/ app11072968

Academic Editor:

Martínez-García Carmen

Received: 18 February 2021

Accepted: 19 March 2021

Published: 26 March 2021

Publisher's Note: MDPI stays neutral with regard to jurisdictional claims in published maps and institutional affiliations.

Copyright: (c) 2021 by the authors. Licensee MDPI, Basel, Switzerland. This article is an open access article distributed under the terms and conditions of the Creative Commons Attribution (CC BY) license (https:// creativecommons.org/licenses/by/ $4.0 /)$.

\begin{abstract}
Incorporation of heavy metal ions in cement hydrates is of great interest for the storage and immobilization of toxic, hazardous, and radioactive wastes using cementitious matrix. Magnesium silicate hydrate (M-S-H) is a low $\mathrm{pH}$ alternative cementitious binder to commonly used Portland cement. Low $\mathrm{pH}$ cements have been considered as promising matrix for municipal and nuclear waste immobilization in the last decades. It is however crucial to assure that the incorporation of secondary ions is not detrimental for the formation of the hydration products. Herein, we investigate the early stages of formation of M-S-H from electrolyte solutions in presence of a wide range of metal cations $\left(\mathrm{Li}^{\mathrm{I}}, \mathrm{Ba}^{\mathrm{II}}, \mathrm{Cs}^{\mathrm{I}}, \mathrm{Cr}^{\mathrm{III}}, \mathrm{Fe}^{\mathrm{III}}, \mathrm{Co}^{\mathrm{II}}, \mathrm{Ni}^{\mathrm{II}}, \mathrm{Cu}^{\mathrm{I}}, \mathrm{Zn}^{\mathrm{II}}, \mathrm{Pb}^{\mathrm{II}}, \mathrm{Al}^{\mathrm{III}}\right)$. The final solid products obtained after $24 \mathrm{~h}$ have been characterized via powder X-ray diffraction (PXRD), attenuated total reflectance-Fourier transformed infrared spectroscopy (FTIR-ATR), elemental analysis via energydispersive X-ray spectroscopy (EDX), scanning electron microscopy (SEM), and high-resolution transmission electron microscopy (HR-TEM). In all the experiments, the main precipitated phase after $24 \mathrm{~h}$ was confirmed to be M-S-H with a ratio (total metal/Si) close to one. The obtained M-S-H products showed strong immobilization capacity for the secondary metal cations and can incorporate up to $30 \%$ of the total metal content at the early stages of M-S-H formation without significantly delaying the nucleation of the M-S-H. It has been observed that presence of $\mathrm{Cr}$, Co, and Fe in the solution is prolonging the growth period of M-S-H. This is related to a higher average secondary metal/total metal ratio in the precipitated material. Secondary phases that co-precipitate in some of the experiments ( $\mathrm{Fe}, \mathrm{Pb}, \mathrm{Ni}$, and $\mathrm{Zn}$ ) were also effectively trapped within in the $\mathrm{M}-\mathrm{S}-\mathrm{H}$ matrix. Barium was the only element in which the formation of a secondary carbonate phase isolated from the M-S-H precipitates was detected.
\end{abstract}

Keywords: low pH cement; magnesium-silicate-hydrate (M-S-H); waste immobilization

\section{Introduction}

Immobilization of heavy metal ions in cement is of great potential for the long-time storage of toxic, hazardous, and radioactive substances originating from industrial processes and incineration of municipal waste [1]. The storage of waste always faces a potential threat of pollutants release and contamination of the environment when deposited in landfills without sufficient pre-treatment. Cementation is a well-established solidification/stabilization (S/S) method used to immobilize of hazardous, toxic, and nuclear waste in solid form [2-7]. A simple processing technique for treating liquid and solid waste helps to minimize the potential migration of hazardous substances and reduces the volume of the disposal units [8]. The availability and the relatively inexpensive nature of the raw 
materials are the key advantages of cement-based S/S methods [9]. The contaminants are encapsulated during the hydration and the hardening of the cementitious materials. The immobilization of metal ions using Portland cement (PC) as encapsulating agent includes chemical and physical mechanisms [10-12]. The physical processes include the immobilization of contaminants through sorption at the surface of the calcium silicate hydrate (C-S-H), the main hydrated product of PC. This mechanism is playing a relevant role in cements that present high surface areas $\left(50-200 \mathrm{~m}^{2} / \mathrm{g}\right)$ and high number of unsaturated sites $[13,14]$. On the other hand, chemical immobilization relies on the incorporation of the ions into the cement matrix/crystal structure itself. This approach aims to change the chemical configuration of the pollutant to achieve materials with lower solubility and reduced hazardousness [15-17]. Reducing the potential for harmful environmental impact of waste disposal through chemical fixation represents a sustainable approach Nevertheless, the distinction between purely chemical and purely physical encapsulation is not straightforward, since heavy metals can interact with the cement paste in different ways (e.g., adsorption, chemisorption, precipitation, ion-exchange, passivation, surface complexation, inclusions, and chemical incorporation) [18].

To develop an appropriate technology for immobilization of toxic materials, parameters like the resistance against an aggressive environment and the chemical compatibility with the waste are essential [19]. As the properties of the wastes vary regarding their composition, the requirements of the cement must be adapted to the specific chemical characteristics. For instance, the highly alkaline porewater in commonly used Portland cement causes high corrosion of metals leading to an undesired $\mathrm{H}_{2}$ generation [20]. Although Portland cement (PC) is known to immobilize metal wastes as precipitated hydroxides, the stability of those highly depends on the internal $\mathrm{pH}$ values and therefore, preventing amphoteric substances from leaching is a severe issue for PC due to its high $\mathrm{pH}(>12)$ [3]. For instance, the optimal $\mathrm{pH}$ value where cement shows the highest retention of metals from fly ash waste lays in between 9 and 11 [6], and therefore the alkaline character of the pore solution during hydration of Portland cement could be unfavorable. Another important issue regarding the use of Portland cement as encapsulating material is that metal ions have been shown to retard the hydration process that yields calcium silicate hydrate (C-S-H) [21]. Regarding the mechanical properties at macroscopic scale, the addition of doping ions to PC has been suggested to alter the bonding strength of the silicate chains of the formed C-S-H, leading to significant reduction of the compressive strength [22].

A potential encapsulating material that meets the $\mathrm{pH}$ requirement is magnesium silicate hydrate (M-S-H). Its relatively low $\mathrm{pH}$ ( 9 to 11$)$ makes it a promising host material as most heavy metals typically show the lowest solubility in the $\mathrm{pH}$ range between 9 and 12 [23]. M-S-H is a magnesium-based cementitious binder analogue to the main products of PC hydration reactions (C-S-H). In the last years, it has caught the attention of researchers as a potential environmentally friendly alternative to ordinary PC [24-28]. In addition to its potential use as a low carbon cement, the suitability of M-S-H for the encapsulation of amphoteric species of waste have also been in focus of various investigations [20,29-31].

The existence of natural magnesium silicate hydrates formed through dissolution and reprecipitation processes of ultramafic rocks suggests the sufficient durability needed for long-term encapsulation [32,33]. M-S-H is also formed upon perturbation of low-pH cement in contact with clayey environment [34]. Regarding incorporation of contaminants, natural magnesium silicate minerals such as sepiolite have demonstrated their ability to entrap heavy metal ions and hazardous organic compounds $[35,36]$. In addition, $U$, $\mathrm{Al}, \mathrm{Sr},{ }^{133} \mathrm{Cs}$, and $\mathrm{Mg}$ from Magnox sludge have been effectively absorbed by synthetic magnesium silicate [20,37-41]. Although there are studies on the characterization of M-S-H cement formed in the presence and absence of several inorganic additives, to the best of our knowledge no detailed description of the early stages of M-S-H crystallization from solution in the presence of metals has been attempted.

The scope of this study is to investigate the crystallization of M-S-H from electrolytic solutions in presence of different metal ions. Based on titration experiments, a first under- 
standing of the early M-S-H formation, especially on retarding and accelerating effects of secondary metal ions on the crystallization of the cement is presented here. The precipitates obtained after the experiments were characterized by powder X-ray diffraction (PXRD), attenuated total reflectance-Fourier transformed infrared spectroscopy (FTIR-ATR), elemental analysis via energy-dispersive X-ray spectroscopy (EDX), scanning electron microscopy (SEM), and high-resolution transmission electron microscopy (HR-TEM) and compared with the pure M-S-H reference (with a $\mathrm{Mg} / \mathrm{Si}$ ratio of approximately one). Understanding how different metal ions affect the early crystallization ( $24 \mathrm{~h}$ ) of M-S-H from solution and obtaining insights into the incorporation mechanism is crucial to further validate the use of M-S-H as encapsulating material depending on the specific composition of the waste.

\section{Materials and Methods}

\subsection{Materials}

Magnesium chloride anhydrous (Sigma Aldrich, Steinheim, Germany (9003-04-7)), sodium metasilicate nonahydrate (Sigma Aldrich, Steinheim, Germany (13517-24-3)) were used as received. For the experiments carried out in the presence of secondary metal cations the following reactants have been used as received: lithium chloride (VWR Chemicals, Leuven, Belgium (7447-41-8)), cobalt(II) chloride hexahydrate (Sigma-Aldrich, Steinheim, Germany (7791-13-1)), iron(III) chloride hexahydrate (Carl Roth, Karlsruhe, Germany (10025-77-1)), lead(II) chloride (Carl Roth, Karlsruhe, Germany (7758-95-4)), chromium(III) chloride hexahydrate (Carl Roth, Karlsruhe, Germany (10050-12-5)), aluminum chloride hexahydrate (Fluka, Sigma-Aldrich, Steinheim, Germany (7784-13-6)), zinc chloride (SigmaAldrich, Steinheim, Germany (7646-85-7)), barium chloride dihydrate (Riedel-de Haen, Seelze, Germany (10326-27-9)), caesium chloride (Merck, Darmstadt, Germany (7647-178), copper chloride dihydrate (Merck, Darmstadt, Germany (10125-13-0), nickel chloride hexahydrate (Sigma-Aldrich, Steinheim, Germany (7791-20-0).

\subsection{Precipitation Experiments}

Crystallization/precipitation experiments were performed using a computer-controlled titration setup supplied by Metrohm (Filderstadt, Germany) with corresponding software (TiAmo ${ }^{\circledR}$ 2.3). The setup consists of two Titrando (Titrando 905, Metrohm No. 2.905.0020) connected to two Dosino devices (Dosino 800, Metrohm No. 2.800.0010) with two $2 \mathrm{~mL}$ burettes dosing units (807, Metrohm No. 6.3032.120). For in-situ monitoring of the reaction progress, the setup was equipped with a $\mathrm{pH}$ electrode (Metrohm No. 6.0233.100), a conductivity probe (Metrohm No. 6.0915.130, with Conductivity Module 856) and a turbidity sensor (Metrohm Optrode No. 6.1115.000).

In a typical crystallization/precipitation experiment, two electrolyte solution (burette $1=\mathrm{MgCl}_{2}$ and burette $2=\mathrm{Na}_{2} \mathrm{SiO}_{3}$ ) with a concentration of $50 \mathrm{mM}$, were added simultaneously to $50 \mathrm{~mL}$ of double deionized water (Milli-Q, resistivity $>18.2 \mathrm{M} \Omega \mathrm{cm}$ ) at a dosing rate of $50 \mu \mathrm{L} / \mathrm{min}$. In the experiments involving the secondary metal cations, a new solution of $10 \mathrm{mM}$ of the corresponding metal salt and $50 \mathrm{mM}$ of $\mathrm{MgCl}_{2}$ was prepared and stored in burette 1 while the sodium metasilicate solution in burette 2 was not modified. Like in the metal-free experiments, both burettes added the solutions simultaneously during the experiments to the reaction vessel containing $50 \mathrm{~mL}$ of double deionized water. The experiments were conducted for a minimum time of $24 \mathrm{~h}$. The solution was stirred at $750 \mathrm{rpm}$ to guarantee homogeneous distribution. To prevent carbonation the Teflon vessel was sealed and purged with Argon continuously during the duration of the experiments. The collected precipitates were centrifuged after experiments and washed twice with double deionized water (Milli-Q, resistivity $>18.2 \mathrm{M} \Omega \mathrm{cm}$ ). The product was cured at $50{ }^{\circ} \mathrm{C}$ under/at room/standard atmosphere for $48 \mathrm{~h}$ and stored in sealed vials inside a desiccator with silica gel at room temperature. For ex-situ analysis the powder samples were prepared as explained below for each technique. 


\subsection{Ex Situ Analytical Methods}

Thermogravimetric analyses (TGA) were carried out on ground powder samples (approx $20 \mathrm{mg}$ ). TGA Netzsch STA 449 F3 Jupiter thermo-gravimetric analyzer (NETZSCHGerätebau $\mathrm{GmbH}$, Selb, Germany) was employed in a temperature range from 30 to $1000^{\circ} \mathrm{C}$ with a heating rate of $10^{\circ} / \mathrm{min}$. Characterization of the crystallinity of the precipitates was performed using a D8 Discover (Bruker AXS GmbH, Karlsruhe, Germany) X-ray diffractometer equipped with $\mathrm{Cu} K \alpha$ radiation $(\lambda=1.5405 \AA)$ at $2 \theta$ range between 0 and $75^{\circ}$ and a scanning rate of $0.016^{\circ} 2 \theta \mathrm{s}^{-1}$. Fourier transformed infrared spectroscopyattenuated total reflectance (FTIR-ATR) was recorded using an Agilent Cary 630 FTIR (Agilent Technologies, Waldbronn, Germany) spectrometer equipped with diamond crystal ATR sampling accessories. Spectra were recorded from 650 to $4000 \mathrm{~cm}^{-1}$. Eight scans were performed for each spectrum with a spectral resolution of $1 \mathrm{~cm}^{-1}$.

Electron microscopy characterization of the final precipitates after experiments was done by scanning electron microscope (SEM) and transmission electron microscope (TEM). SEM imaging was performed using a Zeiss Gemini SEM 500 electron microscope (Carl Zeiss $\mathrm{GmbH}$, Oberkochen, Germany) operated at $2 \mathrm{kV}$ without prior coating of the material. A comparable amount of precipitate for each experiment was deposited on a carbon tape for SEM imaging and elemental analysis.

Semi-quantitative energy-dispersive X-ray diffraction (EDX) analysis were carried out using Zeiss Gemini SEM 500 electron microscope (Carl Zeiss GmbH, Oberkochen, Germany). Analysis was performed at $20 \mathrm{keV}$ accelerating voltage. In these analyses, the spectra are compared with data collected from standards of the manufacturer of the EDX system and stored within the system software. For each sample, EDX- spectra was collected in 50 different points. Acquisition time was $30 \mathrm{~s}$ for each point.

High resolution TEM analysis were performed using a FEI Titan (FEI Europe B.V., Eindhoven, Netherlands) operated at $300 \mathrm{kV}$. M-S-H powders were dispersed in ethanol and carbon coated TEM grids were dipped into the solution and dried in air (60 s) prior to plasma cleaning (10 s). Selected area electron diffraction patterns (SAED) were taken using a $10 \mu \mathrm{m}^{-1}$ aperture collecting data on a circular area of $0.2 \mu \mathrm{m}$ in diameter. Elemental mapping was performed using scanning transmission electron microscopy (STEM) mode with a Super X EDX detector (FEI), composed of four windowless SSD detectors. The scanned areas were also imaged using a high angle annular dark field detector (HAADF).

Inductively coupled plasma optical emission analysis, Agilent Varian, 700 ES (Agilent Technologies, Waldbronn, Germany) was carried out in partially dissolved M-S-H samples to quantify the ratio $\mathrm{Mg} /$ metal for the different experiments, and $2.5 \mathrm{mg}$ of the sample was dissolved in $10 \mathrm{~mL}$ of $1 \mathrm{M} \mathrm{HCl}$ and stored for 2 weeks to ensure complete dissolution of the metal components.

\section{Results}

\subsection{Precipitation Experiments}

In the conducted experiments, the nucleation and precipitation of M-S-H from supersaturated solution was triggered by the simultaneous addition of magnesium chloride solution with a secondary metal cation and silicate bearing solutions into Milli-Q water. Scoping calculations with Phreeqc [42] suggest that the presence of the considered concentration of secondary metal cations should not have a large effect on the solubility conditions. The slight changes in the supersaturation of a magnesium silicate hydrated phase (sepiolite) used as a model M-S-H phase can be neglected based on Phreeqc thermodynamic calculations (results not shown). The $\mathrm{SI}_{\text {sepiolite }}$ was calculated to be about $\sim 8$ at $1000 \mathrm{~s}$ (prior nucleation) for all the simulated experiments in the presence of the secondary metal cations and in the reference experiments.

The onset and advance of the crystallization were monitored by $\mathrm{pH}$ and transmittance measurements (Optrode). The $\mathrm{pH}$ and transmittance data for the reference experiments are plotted versus the magnesium and silicate concentration in solution in Figure 1a. The plots 
represent the averaged values of $\mathrm{pH}$ and transmittance measurements from at least two independent experiments.

In the pre-nucleation stage, the $\mathrm{pH}$ increased from $\mathrm{pH} 6$ (Milli-Q water) to around 10.7 due to the addition of $\mathrm{Na}_{2} \mathrm{SiO}_{3}$ solution. Upon reaching a critical concentration of $\mathrm{Mg}^{2+}$ and silicate species in the media, the nucleation of M-S-H occurred (referred as "nucleation onset" in Figure 1). This was clearly marked by the maximum value of the $\mathrm{pH}$ (Figure 1a, blue line) and the decrease in the transmittance of the solution (Figure 1a, dark grey line). The signal of the transmittance curve was at the maximum at the beginning of the experiments, indicating a clear solution without the presence of particles. Upon nucleation, the fall of the transmittance curve was caused by the increase of the turbidity of the solution/dispersion in which the light can no longer be fully registered by the Optrode due to the scattering by the newly formed M-S-H particles.

After the (quasi-linear) decrease in the transmittance of the solution, the curve approached a constant level by the end of the experiments. The period between the first drop of the transmittance and the reach of the plateau level is referred as "growth period" in this study. The decrease in the transmittance is explained by both increase in the number M-S-H particles and the increase in size of the nuclei. Therefore, this growth period must be considered only as a label for referring to the above-described part of the transmittance curve since it is not possible to distinguish between the nucleation and growth processes with the experimental techniques employed in this study.

a

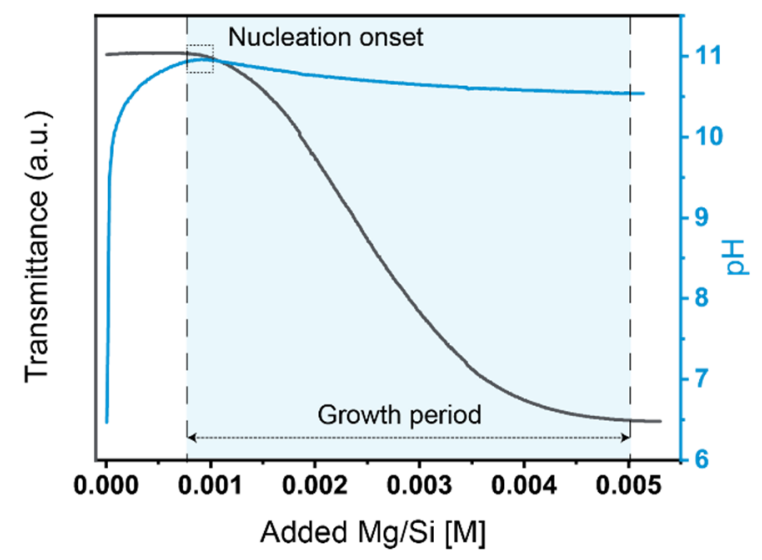

b

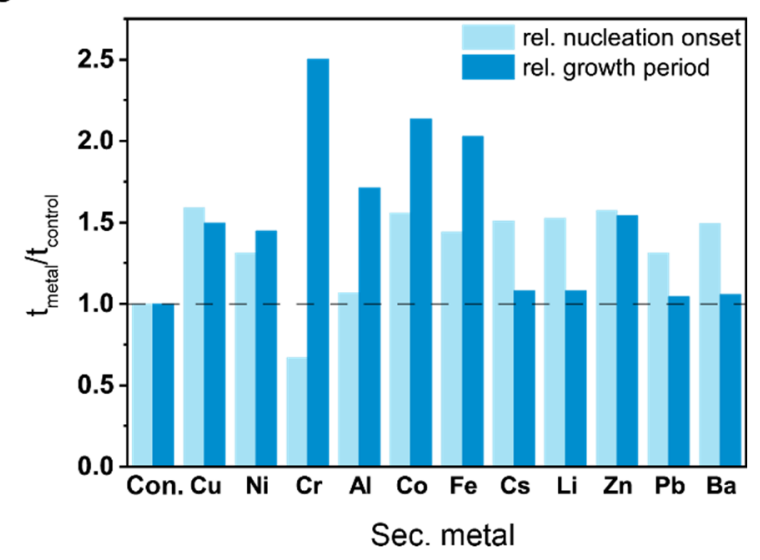

Figure 1. (a) Curve for transmission measurement (dark gray) and $\mathrm{pH}$ for a control experiment with marked nucleation onset (dashed line on the left) and the end of the so-called growth period (dashed line on the right); (b) Nucleation onset and growth period relative to reference experiment determined by transmittance measurements in presence of additive ions.

The influence of the different metal ions regarding the nucleation onset and the growth period can be evaluated by comparing the evolution of the transmittance and $\mathrm{pH}$ between the different experimental runs. Both values presented in Figure $1 \mathrm{~b}$ are calculated relative to the control run $\left(t_{\text {metal }} / t_{\text {control }}\right)$. In any case, it is worth mentioning that the indication of nucleation was slightly earlier detected for transmittance measurement comparing with the $\mathrm{pH}$ electrode. Regarding the nucleation onset (Figure $1 \mathrm{~b}$, light blue column) no trend in relation with the valency of the ions was visible as most of the titrations in presence of secondary metal cations show a delayed onset of the nucleation of ca. 1.5 relative to the control runs where no metals were present. Only $\mathrm{Cr}$ and $\mathrm{Al}$ involving experiments displayed equal or premature onset compared to the pure system. However, comparing the growth period of M-S-H (Figure 1b, dark blue column), the effects were distinct for the different metals. While ions of alkali metal type (Li, and Cs) showed no significant effect, prolongation of the growth period is evident for higher valence ions, with exception of $\mathrm{Ba}$ and $\mathrm{Pb}$. The most outstanding effect with a twofold or longer prolongation has been found for the experiments in the presence of $\mathrm{Fe}, \mathrm{Co}$, and $\mathrm{Cr}$. Interestingly, the prolongation of 
the growth period found in presence of $\mathrm{Fe}, \mathrm{Co}$, and $\mathrm{Cr}$ cations did not result in a delay of nucleation for all of them. For the case of the experiments with $\mathrm{Cr}$, the nucleation event was even accelerated compared to the reference runs. The presence of $\mathrm{Al}$ also caused an extension of the growth period of M-S-H while the onset of nucleation was not affected.

\subsection{Ex Situ Characterization \\ 3.2.1. FTIR}

From FTIR spectra (Figure 2a and full spectra presented in Figure S1) the formation of M-S-H in all samples could be demonstrated. The spectra exhibited a broad band around $3600 \mathrm{~cm}^{-1}$ and a sharper but lower in intensity band at $1650 \mathrm{~cm}^{-1}$ associated with $\mathrm{H}_{2} \mathrm{O}$ vibrations. A detailed view of the characteristic area for silicate vibrations from $1200-800 \mathrm{~cm}^{-1}$ is presented in Figure 2a. These different bands are a result of varying interconnection degree of the silica tetrahedra (from $\mathrm{Q}^{0}$ where there are no bridging oxygen atoms per tetrahedron to $\mathrm{Q}^{4}$ where the four oxygens are shared). The main band from 1100 to $950 \mathrm{~cm}^{-1}$ is related to the $\mathrm{Si}-\mathrm{O}$ stretching vibrations of $\mathrm{Q}^{3}[27,28]$. The fact that mainly $\mathrm{Q}^{3}$ silicate sites have been observed in M-S-H confirms the layered silica structure like that found in clay minerals. The band located around $950-870 \mathrm{~cm}^{-1}$ corresponds to the $\mathrm{Q}^{2}$ Si-O antisymmetric stretching vibration $[25,43,44]$. It is worth noting that the formation of brucite $\left(\mathrm{Mg}(\mathrm{OH})_{2}\right)$ with a characteristic band at $3698 \mathrm{~cm}^{-1}$ was neither detected by FT-IR or XRD although the $\mathrm{pH}$ values were measured above 10.5 .

a

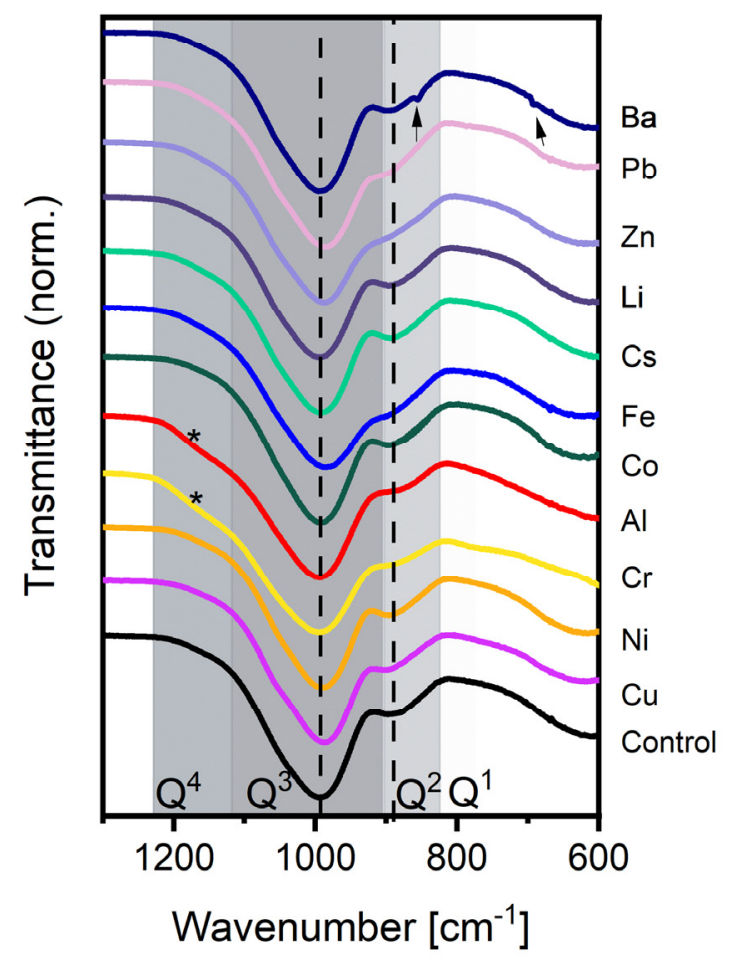

b

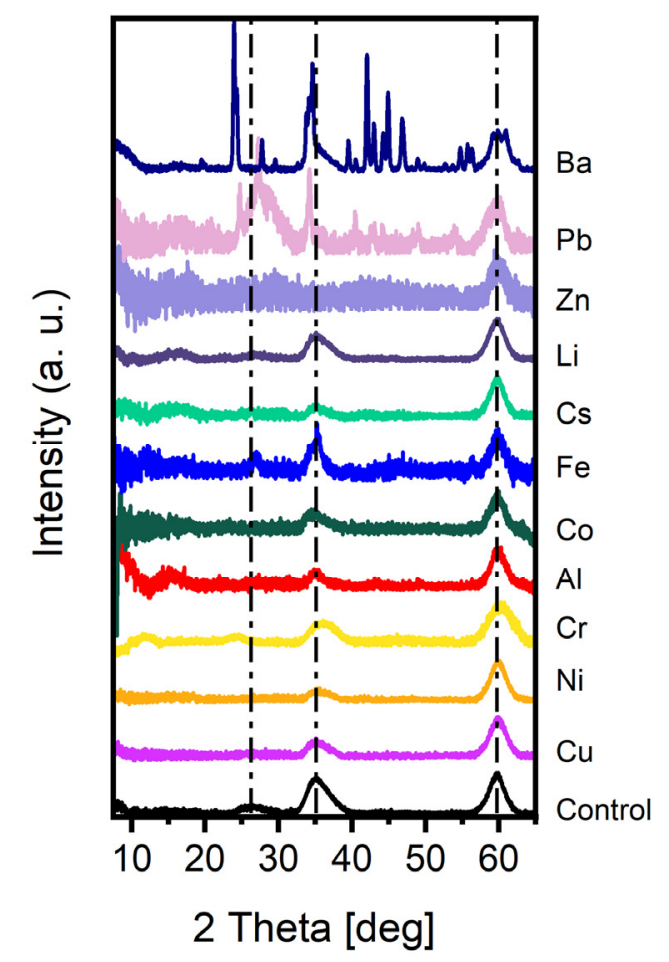

Figure 2. (a) Fourier transformed infrared spectroscopy (FTIR) spectra of M-S-H with additive ions. * mark shoulders belonging to $\mathrm{Q}^{4}$ silica networks and arrows bands at 960 and $690 \mathrm{~cm}^{-1}$ from carbonate groups in the Ba sample; (b) X-ray diffraction (XRD) diffraction pattern for M-X-S-H normalized to the reflex at $59.9^{\circ} 2$ theta.

The FTIR spectra of M-S-H obtained in presence of secondary metal cations were comparable to the FTIR of the M-S-H obtained in the control experiment (Figure 2a) indicating the formation of M-S-H in all the cases. Only the $\mathrm{Fe}, \mathrm{Cr}$, and $\mathrm{Zn}$ containing precipitates show a stronger overlap between the $Q^{2}$ and $Q^{3}$ bands than other samples because of a shift of the $\mathrm{Q}^{2}$ band to higher wavenumber. In the meantime, a shoulder in the 
$\mathrm{Q}^{4}$ region $\left(>1190 \mathrm{~cm}^{-1}\right)$ appeared and the broad band at $615 \mathrm{~cm}^{-1}$ was less pronounced in spectra obtained for the precipitates containing $\mathrm{Cr}$ and $\mathrm{Al}$. In the case of product obtained in the presence of Ba, weak bands in the range $1400-1500 \mathrm{~cm}^{-1}$ and 960 and $690 \mathrm{~cm}^{-1}$ pointed to impurities originating from carbonate groups.

\subsubsection{PXRD}

All the collected PXR diffractograms normalized to the reflection at $59.9^{\circ} 2 \Theta$ are presented in Figure $2 b$. The diffractogram measured for control experiment (i.e., secondary metal-free scenario) displays the reflex peaks at characteristic regions, (20-26.7, 35, and 59.9) characteristic for M-S-H $[25,27]$. The broadness of the peaks and low signal intensity indicated the nano-crystalline nature of M-S-H precipitates in most samples [45]. In general, the low signal made it difficult to precisely identify all reflections below $25^{\circ} 2 \Theta$ in most of the samples.

Secondary phases co-precipitated in the some of the samples. In contrast to the control, the pattern of the $\mathrm{Ba}$ and $\mathrm{Pb}$ containing samples showed defined additional reflections indicating the presence of other crystalline phases apart from M-S-H. In the case of the Ba sample, the presence of sharp peaks confirmed that barium carbonate [46] precipitated along with the M-S-H. For the Pb containing sample, this was also the case and traces of hydrated lead carbonate hydrocerrusite [47] appeared based on the XRD analysis. The co-precipitation of carbonated phases evidenced that the continuous purging with Argon used during the experiments did not completely suppress the diffusion of $\mathrm{CO}_{2}$ at the $\mathrm{pH}$ range of our experiments. In the case of the Fe samples, some rather undefined peaks merged from the typical pattern of M-S-H at 34.5, 35.25, and $39.35^{\circ} 2 \Theta$. However, due to the low signal to noise ratio, identification of the co-precipitated Fe-phase was not possible from XRD. The position of the reflection peak suggests the presence of iron oxide phase(s) which was confirmed by SAED analysis by TEM on the obtained material (see below).

\subsubsection{Thermogravimetric Analysis (TGA)}

The TGA and the derivative of the weight loss are presented in Figure $3 a, b$ respectively, for the control sample together with the precipitates obtained in presence of secondary metal cation. TGA of the control sample presented the corresponding multi-step mass loss reported for synthetic M-S-H $[27,28,48]$. The first mass loss from 40 to $300^{\circ} \mathrm{C}$ was associated with the physically bound interlayer water and is strongly related to the drying methods of M-S-H [28]. The weight loss in this region indicated a percentage of physically bound water for the control M-S-H samples of ca. 16-17\%. The second loss of mass from 300 to $790^{\circ} \mathrm{C}$ was due to the evaporation of structurally bound water in the M-S-H in the form of hydroxyl groups ( $\mathrm{Mg}-\mathrm{OH}, \mathrm{Si}-\mathrm{OH})$. In this region, control experiments exhibited a loss of ca. $10-11 \mathrm{wt} . \%$. Regarding the precipitates obtained in the presence of secondary metal cations, (excepted for the $\mathrm{Pb}, \mathrm{Cr}$, and $\mathrm{Al}$ containing samples), the content of physically bound water $\left(30-300{ }^{\circ} \mathrm{C}\right.$ ) ranged from ca. $17 \mathrm{wt} . \%$ to $21 \mathrm{wt} . \%$ following the same water loss shape than the control sample (metal-free). For those precipitates the second weight loss related to the hydroxylation was also similar (both in \% and in shape) to the control sample, indicating that no clear proofs of extra specific hydroxide phases by TGA. The Ba containing samples showed an additional last step over $790^{\circ} \mathrm{C}$, probably associated with the decomposition of co-precipitated Ba carbonate phases. 


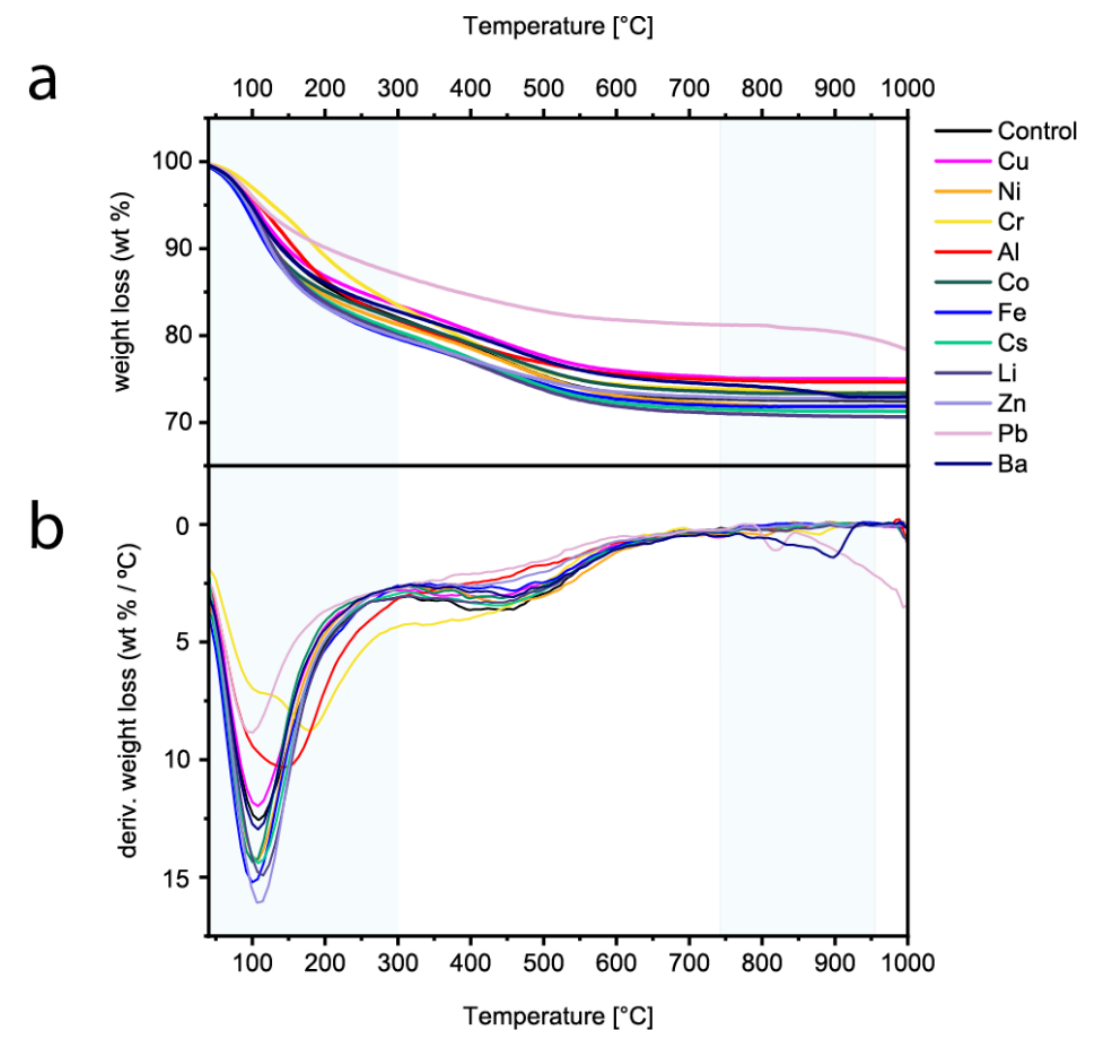

Figure 3. (a) Thermogravimetric data weight loss in $\%$ from 40 to $100{ }^{\circ} \mathrm{C}$; (b) derivative weight loss in $\% /{ }^{\circ} \mathrm{C}$.

The $\mathrm{Pb}$-containing samples contained only ca. half of the physically bound water and half of the chemically bound water compared to M-S-H samples, while an additional small last step over $800{ }^{\circ} \mathrm{C}$ was found.

For Al containing samples this step became broader and slightly shifted to higher temperatures (shift about $\sim 50{ }^{\circ} \mathrm{C}$ ). At the same time, the second weight loss attributed to the dehydroxylation seemed to occur at lower temperature. This could be due to the presence of amorphous $\mathrm{Al}(\mathrm{OH})_{3}[49,50]$ and/or hydrotalcite [49].

Finally, the $\mathrm{Cr}$ containing samples showed a second weight loss centred at $175{ }^{\circ} \mathrm{C}$ in addition of the physically water loss, probably related to the presence of amorphous $\mathrm{Cr}(\mathrm{OH})_{3}$ and/or double layered hydroxide similarly to the precipitates obtained in the presence of $\mathrm{Al}$.

\subsubsection{SEM}

The precipitates obtained in the experiments were also analyzed by SEM to evaluate possible morphological changes of the M-S-H particles when the secondary metal cations were present during the crystallization. The typical M-S-H product with globular morphology was obtained in most of the samples (Figure 4). Round particles with an elevated size dispersion stick together to form larger agglomerates that were present in all the precipitates [25,51]. For most samples, no difference in the structure and morphology of the obtained material could be observed via SEM as they are all akin to the M-S-H formed in the absence of secondary metal cations. The most distinct changes in the precipitates were the presence of secondary crystals in Ba containing samples where larger micron-sized crystals of barium carbonate (identified by XRD) were found together with M-S-H globules (Figure $4 \mathrm{~d}$ ). In the case of the precipitates obtained in the presence of $\mathrm{Al}$, the formation of interconnected micrometre-sized lamellar structures that resemble desert-rose particles was promoted, alongside M-S-H globules (Figure 4f). 


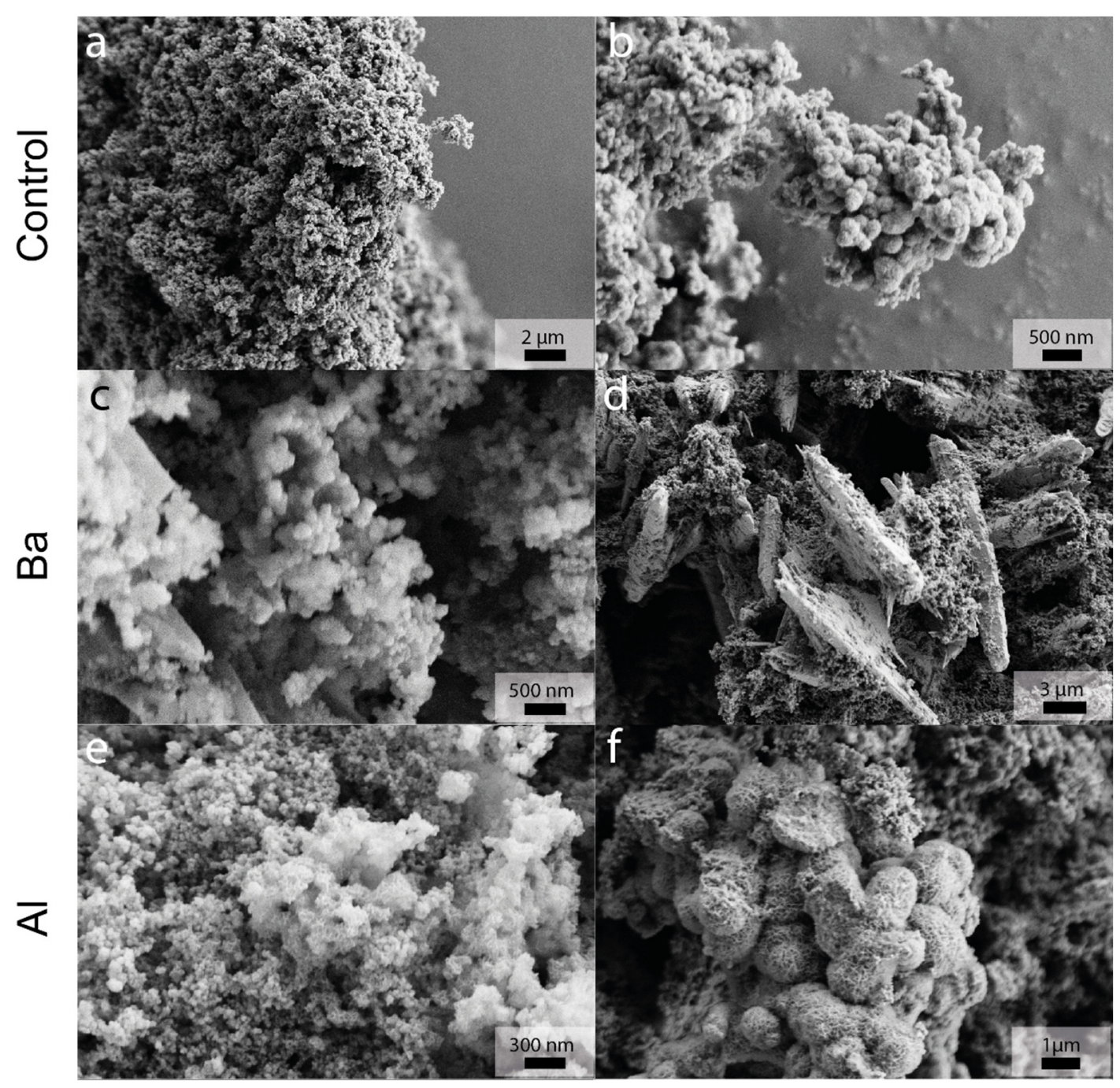

Figure 4. Scanning electron microscopy (SEM) images of the precipitated crystals (a,b) pure M-S-H; (c,d) Barium containing M-S-H and barium carbonate; (e,f) aluminum-containing M-S-H.

\subsubsection{TEM}

Due to the nanometre size of the individual M-S-H globules, TEM was used to further investigate the precipitates regarding size, shape, and surface features. Agreeing with the SEM analysis, the TEM micrographs (Figure 5a) depicts pure M-S-H as agglomerates of poorly crystalline (Figure 5a, inset) spherical particles. A closer look (Figure 5b) reveals that the surface of globular particles is formed by a large amount of interconnected foil-like structures, which yield to a rough and porous surface. Similar foils or lamellar structures have been observed in the synthesis of hollow M-S-H spheres from silica globules [26,52,53]. EDX elemental mapping confirmed that $\mathrm{Mg}$ and $\mathrm{Si}$ are homogeneously distributed over the particles (Figure $5 \mathrm{c}(\mathrm{i}-\mathrm{iv})$ ).

In general, the morphology of the most M-S-H precipitates obtained in the presence of different secondary metal cations are comparable to the reference samples (Figure 5), however subtle differences were observed. The globular M-S-H precipitates obtained with Fe (Figure $5 \mathrm{~d}-\mathrm{f}$ ), $\mathrm{Pb}$ (Figure $5 \mathrm{~g}-\mathrm{i}$ ), and $\mathrm{Cr}$ (results not shown) do not possess a rough foil-like structure but rather irregular cloud-like morphologies. In the case of $\mathrm{Cu}, \mathrm{Co}$, and Zn containing samples, both foil-like and cloud-like morphologies were found (Figure S2). The M-S-H precipitates formed in the presence of $\mathrm{Cs}, \mathrm{Li}, \mathrm{Ni}$, and $\mathrm{Ba}$ are analogous to the control M-S-H material. For samples obtained in the presence of $\mathrm{Cs}$, the foil-like structure is more developed (Figure $5 \mathrm{j}-1$ ) than in the rest of the samples and in control runs, despite 
the homogeneous distribution of the Cs in the material and the low amount incorporated (Figure 5l(iii)). Unlike SEM analysis which uncovered the presence of "desert-rose-like" structures, no significant changes were found for samples containing Al observed under TEM (Figure S2). The SAED also reveals an amorphous structure with a homogeneous distribution of $\mathrm{Al}$ throughout the material (Figure S2).

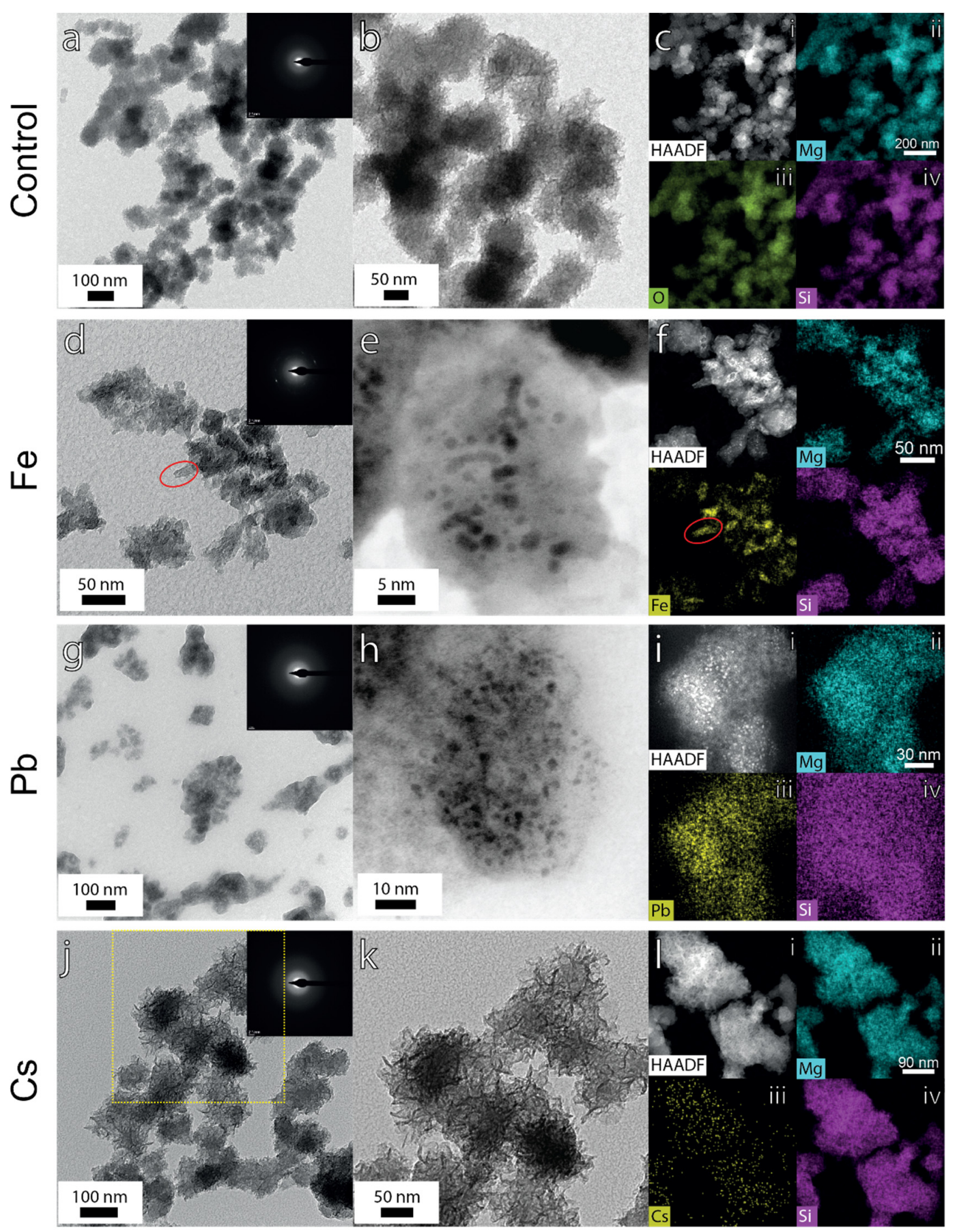

Figure 5. Transmission electron microscopy (TEM) images of precipitated crystals (a,b) pure M-S-H system with selected area electron diffraction (SAED) pattern inset; (c(i-iv)) elemental mapping of the pure M-S-H; (d,e) Fe-containing M-S-H samples SAED pattern inset; (f(i-iv)) elemental mapping of Fe-containing M-S-H, red ellipse highlight Fe-rich regions within the M-S-H matrix; (g,h) Pb-containing M-S-H samples SAED pattern inset; (i(i-iv)) elemental mapping of Pb-containing M-S-H; (j) Cs-containing M-S-H samples SAED pattern inset; $(\mathbf{k})$ zoom into the yellow square in (j); $(\mathbf{l}(\mathbf{i}-\mathbf{i v}))$ elemental mapping of Cs-containing M-S-H. 
In the case of the Fe containing samples, the EDX analysis showed that even if Fe was detected everywhere in the precipitates, there were some elliptical areas (ca. 20-30 nm in length) in which Fe was enriched and significantly lower amounts of $\mathrm{Mg}$ and Si were detected (red ellipse in Figure 5a,f (iii)). In addition, the SAED of Fe bearing precipitates on those areas where higher amount of Fe was detected possess additional distinct reflexes evidencing crystalline solids within the M-S-H matrix (Figure 5d, inset). Analysis of the SAED (d-spacings of ca. $1.45 \AA$ and $2.6 \AA$ ) together with XRD and EDX mapping suggest the presence of an iron oxide phase(s) within M-S-H precipitated material [50]. It is worth mentioning, that no iron oxide particles were found outside the M-S-H matrix. Interestingly, $\mathrm{HAADF}$ images of $\mathrm{Pb}$ and Fe samples both display the existence of ca. 2-5 nm sized particles with higher electron contrast, embedded in the amorphous M-S-H matrix (Figure 5e,h (black spots)). These nanocrystals were uniformly distributed in both samples. Unlike the Fe-containing samples, EDX-elemental analysis show that $\mathrm{Pb}$ was distributed homogeneously within the matrix of the Pb-bearing samples (Figure $5 \mathrm{~h}, \mathrm{i}$ ) and SAED reveals its amorphous nature (Figure $5 \mathrm{~g}$, inset).

\subsubsection{Compositional Analysis of the Precipitates}

Energy dispersive X-ray (EDX) elemental analysis was carried out in the M-S-H precipitates and inductively coupled plasma optical emission spectroscopy (ICP-OES) analysis was performed on the dissolved M-S-H precipitates to estimate their compositions. It must be pointed out that to obtain reliable quantitative analysis of samples with SEM-EDX, an accurate calibration is necessary. Furthermore, the sample should be homogeneous within the interaction volume, perfectly flat (polished), and normal to the incident beam as well as stable under the electron beam, which is not the case in our measurements. Nevertheless, semi quantitative elemental data for M-S-H can be obtained from EDX analysis too. Fifty representative points were measured within locations identified visually as M-S-H precipitates. A homogenous distribution of the fifty points all over the sample was pursued by the operator. EDX analysis has been widely used in the cement community to estimate the composition of hydrated products, due to the advantage of being coupled to SEM imaging, which allows the selection of specific areas of the sample for analysis [24,40,54].

The relative composition of $\mathrm{Mg}, \mathrm{Si}$, and secondary metal (50 measurement points per sample) is depicted in Figure S3 for each sample. Most of the samples show consistent values with no significant variation of $\mathrm{Mg}$, $\mathrm{Si}$, and secondary metal relative content among the 50 points. However, in the case of precipitate obtained in the presence of $\mathrm{Ba}, \mathrm{Zn}, \mathrm{Co}$, and $\mathrm{Ni}$, considerably higher variation in the relative metal content (up to $80 \%$ for $\mathrm{Ba}$ ) were measured (and consequently lower $\mathrm{Mg}$ and $\mathrm{Si}$ ) resulting in two distinct trends in the EDX measurements (Figure S4). In Figure 6a, the average total metal (Mg + secondary metal) to Si ratio obtained from the EDX measurements are presented. Two different sets of values are depicted: the average of the 50 measured points (first column Figure 6a) and the so called "corrected" average values (second column Figure 6a) in which the highest 10 values have been neglected as we consider that they correspond to the secondary non-M-S-H phases (Figure S4b), and thus they do not represent the incorporation of the metals within the M-S-H. In the special case of precipitates obtained with Ba (Figure S5), the formation of two distinct phases is astonishingly clear and the highest 20 points were neglected to obtain reliable estimate for the Ba content in the M-S-H (Ba* in Figure 6a,b).

The compensation/exchange of $\mathrm{Mg}$ with the complementary metals results in an overall metal ion content quasi equal to the content precipitated in the control experiments. The average $\mathrm{Mg} / \mathrm{Si}$ ratio in the reference samples was close to one. In general, all the obtained average values were close to one for most of the samples; however, when considering all 50 values, the total metal/Si ratio is higher for $\mathrm{Ba}, \mathrm{Zn}, \mathrm{Co}$, and Ni probably due to the presence of secondary phases that are distributed over the sample. Correction neglecting the highest 10 values, further confirm that the presence of the complementary metals does not significantly influence the total metal/Si ratio. As can be seen from the ternary plot, constructed using the EDX "corrected" values (Figure 6b), the compositions of the M-S-H 
precipitates do not vary significantly regarding the Si content (ca. 50\%) and only changes in the $\mathrm{Mg} /$ secondary metal ratio are observed. Regarding the monovalent elements tested (Cs, and $\mathrm{Li}$ ), it should be noted that $\mathrm{Li}$ was not possible to measure with EDX and Cs seems to not be incorporated.
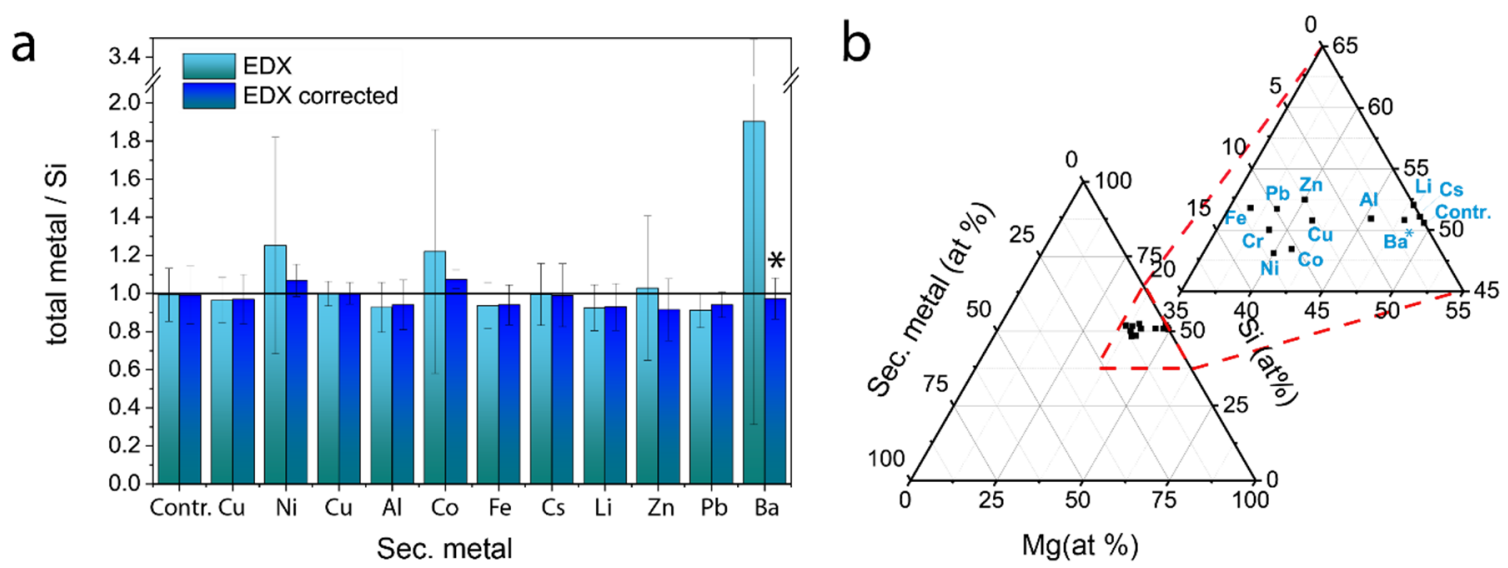

Figure 6. (a) Comparison of the total metal ( $\mathrm{Mg}+$ secondary metal) to Si ratio measured via energy-dispersive $\mathrm{X}$-ray spectroscopy (EDX). (b) Ternary plot of the Mg-Si-secondary metal composition in atomic \% for the precipitated samples measured with EDX. *: corrected total metal /Si ratio for M-S-H containing Ba neglecting the highest 20 values.

The ICP measurements show that the elements $\mathrm{Al}, \mathrm{Fe}$, and Co were the most incorporated secondary metal in the precipitated samples (Figure S6, first column). Regarding the ratio of secondary metal/total metal, most of the samples $(\mathrm{Cu}, \mathrm{Cr}, \mathrm{Co}, \mathrm{Fe}$, and $\mathrm{Pb})$ exhibit a good agreement between both independent techniques (Figure S6). For the case of the monovalent elements, Cs concentration was under the detection limit for this element via ICP-OES $(1 \mathrm{ppm}=7.5 \mu \mathrm{M})$ supporting with EDX analysis that no or little Cs was present in the solid phases. Li was analyzed by graphite furnace atomic absorption spectroscopy (GFAAS) since it was not possible to measure with ICP-OES. The obtained value was strikingly low at $4.14 \mathrm{ppb}(0.6 \mu \mathrm{M})$ and therefore likely not incorporated in the solids. For $\mathrm{Ba}, \mathrm{Zn}, \mathrm{Ni}$, and $\mathrm{Al}$ bearing samples, there are some significant deviations between EDX average data (considering the 50 measurement points, Figure S6, second column) and ICP-OES data (Figure S6, first column).

In the case of the precipitates formed with $\mathrm{Ni}, \mathrm{Zn}$, and $\mathrm{Ba}$, the relative average secondary metal/total metal ratios obtained from EDX considering 50 points (Figure S6, second column) are considerably higher than the ones obtained by ICP-OES Figure S6, first column). However, the comparison of the values measured with ICP-OES with the corrected values (Figure S6, third column) for $\mathrm{Ni}$ and $\mathrm{Zn}$ depicts a better agreement regarding the secondary metal/total metal ratio in the samples. In the Al-bearing samples, the opposite occurs, and the ICP-OES values of $\mathrm{Al} /(\mathrm{Al}+\mathrm{Mg})$ were significantly higher compared to the ratio obtained from EDX data. Surprisingly, in this sample, the presence of a co-precipitated phase was not evident from EDX analysis. It is worth noting that the two techniques give us complementary data and they both have analytical advantages and drawbacks. EDX is a spatially resolved measurement technique and thus, we attempted to focus on the M-S-H precipitates at 50 different locations seeking for a homogenous distribution within the sample. However, as was mentioned at the beginning of this section, there are some significant drawbacks, and it must be considered as a semi quantitative technique for the system studied. In contrast, the ICP-OES measurements give us an accurate concentration of all elements in the precipitates that have been dissolved in the $1 \mathrm{M} \mathrm{HCl}$ solution. The values obtained by ICP-OES provide a precise estimation of the total concentration of elements in solid precipitates without being able to distinguish the contribution of metals incorporated in M-S-H and the metals that might have precipitated 
in other phases. A summary of the secondary metal/total metal ratio obtained by ICP-OES and EDX is reported in Table S1.

\section{Discussion}

The early stages of M-S-H crystallization in the presence of secondary metal cations were investigated by stepwise addition of magnesium (and secondary metal cations) and silicate to double distilled water. The nucleation of M-S-H occurs when a pH ca. 10.5-11 is reached. Within this $\mathrm{pH}$ increase, most oxy-hydroxyl-heavy metal carbonates overcome their solubility product and therefore may precipitate together with M-S-H. At the onset of nucleation, the $\mathrm{pH}$ value reaches its maximum and then decreases slowly approaching to a quasi-constant value (Figure 1a). The decrease in $\mathrm{pH}$ would agree with the consumption of the silicate species - and the incorporation of $\mathrm{OH}^{-}$into the $\mathrm{M}-\mathrm{S}-\mathrm{H}$ structure. Speciation modelling with Phreeqc suggests that most of the secondary metal cations exist as metal hydroxides species in the prenucleation stage due to the increased alkalinity of the media (Figure S7). Cs, Li, and Ba are the only elements predominantly present as free ions in solution prior to M-S-H nucleation according to the thermodynamic modelling. The rest of the secondary metal ions mostly exist as metal hydroxide species or metal oxyanions. Interestingly, the secondary metals cations that does not form complexes were incorporated in the M-S-H to a lesser extent (almost negligible), based on our compositional analysis. This suggests that the incorporation of metal hydroxides or metalloid oxy-anions species into M-S-H is preferred over the incorporation of free metal cations tested in this study.

The delay in the onset of nucleation relative to the reference run (marked by the $\mathrm{pH}$ and transmittance drop) was comparable (ca. 1.5) for most of the elements. Contrary, in the system with $\mathrm{Cr}$, the nucleation event was accelerated compared to the reference runs. Thus, it can be envisaged that no strong retardation effects in the early formation of the hydration products is expected when using M-S-H to immobilize the metal cations investigated here. Concerning the growth period (when transmittance reached a constant plateau level), its prolongation was not always linked to a delay in the nucleation. This highlights that the early stages of M-S-H crystallization could be affected uniquely by different metal cations regarding nucleation and early growth stages. The distinct outcome for the nucleation onset and the prolongation of the growth period can be strongly dependent on the chemical speciation of metal cations incorporated in the M-S-H, the mechanism of incorporation, and the formation of secondary phases. The retardation in the growth period $(\mathrm{Cr}, \mathrm{Co}$, and $\mathrm{Fe})$ is related to a higher secondary metal/total metal average ratio in the precipitated material measured by EDX (Figure S6). This could be caused by a mechanism of immobilization where the formation of nanometre sized secondary metal hydroxide phases which are trapped in the M-S-H matrix, plays a more decisive role than in the other tested secondary metals. Previous studies attribute the retardation effect in $\mathrm{M}-\mathrm{S}-\mathrm{H}$ formation in the presence of $\mathrm{Sr}^{2+}$ to the precipitation of $\mathrm{Sr}(\mathrm{OH})_{2}[40,55]$. The competition for hydroxyl ions to form secondary metal hydroxide phases could extend the growth period of M-S-H.

The presence of additives is not only impacting the kinetics of crystal growth but also the composition and structural motifs of the final cement hydrated product. The main precipitated phase formed in all the experiment is a poorly crystalline M-S-H, which displays the typical globular morphologies observed in previous studies $[24,51,56]$. Except for the precipitates obtained with $\mathrm{Li}$ and $\mathrm{Cs}$, which do not seem to be incorporated into the M-S-H (on the time scale of our experiments), the other metal cations studied are immobilized in the precipitated solids. Formation of secondary phases was confirmed with XRD, SEM, and TEM for the system with $\mathrm{Ba}, \mathrm{Pb}$, and Fe and suggested for the systems with $\mathrm{Ni}$ and $\mathrm{Zn}$ based on EDX-analysis. The formation of barium carbonate was observed in the system with $\mathrm{Ba}$, where large $\mathrm{BaCO}_{3}$ crystals were found along with M-S-H samples. This observation suggests co-precipitation of $\mathrm{BaCO}_{3}$ and $\mathrm{M}-\mathrm{S}-\mathrm{H}$ phases composing a mechanical mixture in the precipitate. However, in the system with Fe, the nanometric iron oxide precipitates were trapped within the M-S-H matrix. The minute size of Fe hydroxides (tens of nm, Figure 5) most likely allows an easy incorporation of this 
phase into the growing M-S-H particles. This behavior suggests an incorporation of $\mathrm{Fe}^{\mathrm{III}}$ via an absorption mechanism. The hydrocerrusite phase detected by XRD could neither be identified by SEM nor TEM, suggesting that it was also homogenously incorporated into the M-S-H matrix and distributed over the sample at nanoscale and thus no differences were apparent in the EDX mapping analysis. The formation of the carbonated phases in the experiments with $\mathrm{Ba}$ and $\mathrm{Pb}$ is not fully understood but could also be explained by $\mathrm{CO}_{2}$ contamination during centrifugation, washing, and/or drying procedure. The coprecipitation of witherite together with M-S-H highly affects the average values obtained with EDX analysis as depicted in Figure 6. The presence of two distinct phases is obvious from the EDX analysis (Figure S5): a barium-rich phase (most likely witherite) and a phase where the barium was negligible (M-S-H). In comparison with ICP-OES data, the 50 points average $\mathrm{Ba} /(\mathrm{Ba}+\mathrm{Mg})$ ratio obtained by EDX-analysis is considerably higher, which can be attributed to the arbitrary selection of measurement locations by the operator. This in turn may have resulted in the analysis of witherite particles buried within M-S$\mathrm{H}$ precipitates or mixed with them in more than $40 \%$ of the measurements (Figure S6). However, when calculated the $\mathrm{Ba} /(\mathrm{Ba}+\mathrm{Mg})$ ratio by neglecting the first 20 points measured by EDX (Figure S6, third column *), the discrepancy between the average ratio calculated with ICP and EDX data is highly reduced, indicating that witherite was not the most abundant phase in the precipitates. The EDX analysis for Pb and Fe samples suggests that those secondary phases were present in a minor amount and their distribution within the M-S-H matrix was more homogeneous. In the system with $\mathrm{Ni}$ and $\mathrm{Zn}$, neither XRD nor TEM evidence the formation of secondary phases which hints again to their minor presence in the sample. The arbitrary selection of locations for the EDX-analysis might have uncovered the existence of those resulting in the higher average values measured by EDX (Figure S6, second column) compared to ICP-OES (Figure S6, first column). The corrected ratio of (secondary metal/total metal) agrees well with the ICP-OES data supporting the minor presence of the $\mathrm{Ba}, \mathrm{Pb}, \mathrm{Fe}, \mathrm{Ni}$, and $\mathrm{Zn}$ secondary phases.

In the system with $\mathrm{Al}, \mathrm{XRD}$ data are identical to the one collected in the reference M-S$\mathrm{H}$ experiment. This agrees with recent studies that proved the incorporation of $\mathrm{Al}$ in both silica and magnesium oxide layers in M-S-H structure without inducing changes detectable in the XRD pattern [54]. FTIR analysis also indicate that the structure of the obtained M-S-H precipitates is weakly affected by the incorporation of Al. The slight shoulder in the $\mathrm{Q}^{4}$ region indicated that some of the silicate tetrahedra could be connected to each other than to a metal ion (presence of amorphous silica) compared with the reference M-S-H precipitates. The substitution of $\mathrm{Al}$ for Mg measured by EDX is ca. $10 \%$ which is lower comparing with the other metals (except Cs and Li). However, compositional analysis (EDX/ICP) of this sample shows rather high uncertainty regarding the ratio $\mathrm{Al} /(\mathrm{Al}+\mathrm{Mg})$ in the precipitated material. This high discrepancy between both techniques is difficult to explain, considering the coherent values obtained by EDX analysis (Figure S3). It is worth noting that EDX data for Al content are less reliable due to the lower sensitivity of this method to light elements. However, the presence of a co-precipitated phase as a hydrotalcite-like phase, not identified by SEM/EDX due to arbitrary selection of locations, in which the amount of $\mathrm{Al}$ and $\mathrm{Mg}$ would be considerably higher than in the $\mathrm{M}-\mathrm{S}-\mathrm{H}$ precipitates is the most acceptable reason for these differences. The precipitation of the semi-amorphous hydrotalcite was recently observed in addition of M-A-S-H phases [57].

Our experiments demonstrated that there are different mechanisms involved in the incorporation of the secondary metals in M-S-H. These mechanisms are controlled by properties of ion association (i.e., aqueous speciation and surface complexation) and the solubility of the secondary phases. This study shows that the mechanism behind the phenomena of absorption and coprecipitation controls the inclusion of the secondary metal cation into the M-S-H matrix. The combination of these effects explains the element specific incorporation mechanism characteristic to each ion considered in this study. However, a common tendency to delay the nucleation onset of M-S-H has been observed in presence of secondary metal cations. Recent studies which investigated the solid stabilization of 
$\mathrm{Pb}$ using magnesium oxychloride cement and magnesium phosphate cement proposed that in general, metals are immobilized as precipitated amorphous metal hydroxides in those Mg-based cementitious materials [31]. In the obtained precipitates, amorphous metal hydroxides could certainly be present in the form of nanoparticles distributed homogeneously through the M-S-H matrix. In this case, the resolution of the applied experimental techniques (EDX-TEM) would not allow detecting these particles in the MS-H matrix. It can be speculated that the nanoparticles (ca. $2-5 \mathrm{~nm}$ ) with higher electron contrast present in the precipitates formed from $\mathrm{Pb}$ and Fe bearing solutions could be metal hydroxide phases of both ions trapped in the M-S-H matrix. However, the resolution of the applied analysis cannot evidence the difference in their composition. Another possibility is the incorporation of the metal cations within the semicrystalline structure of M-S-H. Assuming a sepiolite-like M-S-H, the metals are expected to be preferentially incorporated in the so-called exchangeable sites (i.e., surface of particles and interlayer) replacing the $\mathrm{Mg}$ ions. However, as has been shown for $\mathrm{Al}$, they also can be incorporated in both $\mathrm{SiO}_{2}$ and $\mathrm{MgO}$ layers [54]. Based on our results, it seems that the mechanism of incorporation could vary significantly for the different metals. The fact that the overall $(\mathrm{Mg}+$ metal $) / \mathrm{Si}$ corrected ratio (Figure 6, second column) is not far from the $\mathrm{Mg} / \mathrm{Si}$ ratio in the reference $\mathrm{M}$ $\mathrm{S}-\mathrm{H}$ for most of the samples could be interpreted as isomorphic substitution of cations for $\mathrm{Mg}$. Nevertheless, this mechanism is postulated under the assumption that no secondary phases are embedded in the M-S-H matrix. Mechanistic understanding of the incorporation mechanism for each element would require detailed analysis of the cation exchange capacity (CEC) and structural characterization such as solid state nuclear magnetic resonance (SSNMR) and/or pair distribution function analysis (PDF). In this context, the reversibility studies would be pivotal for elucidating the mechanism of immobilization and thus, are in the focus of ongoing studies.

\section{Conclusions}

The influence of secondary metal ions on the early stages of M-S-H crystallization was evaluated in titration experiments. The simple experimental setup provides well reproducible data, and thus can be recommended for future studies as a "fingerprinting technique" to study the effects of additives such as metal cations on the formation of M-S-H in reliable manner. Obtained results showed the large capacity of M-S-H based cements for the immobilization of metal cations at the early hydration stages. The retardation effect regarding the formation of magnesium silicate hydrated products was not significant in the presence of secondary metal cations. However, the growth period of the precipitates was extended considerably for $\mathrm{Fe}, \mathrm{Co}$, and $\mathrm{Cr}$. This opens a wide range of options for efficient control of early M-S-H crystallization by selecting the specific additives, which can be active at different stages of the early formation of M-S-H. In addition, it could be shown that most elements were incorporated into the M-S-H structure without inducing significant changes in the morphology of the precipitates. Even in presence of secondary phases co-precipitated ( $\mathrm{Fe}, \mathrm{Pb}, \mathrm{Zn}$, and $\mathrm{Ni}$ ), those phases were immobilized in the $\mathrm{M}-\mathrm{S}-\mathrm{H}$ matrix. Ba was the only cation in presence of which the formation of a secondary carbonate phase isolated from the M-S-H precipitates was detected.

Systematic screening of the effect of metals in the early crystallization of M-S-H showed that the immobilization at these stages can already be significant for some of the tested metals. Unravelling the specific mechanism of incorporation into the M-S-H matrix remains a challenge that would require the information provided in this manuscript as well as a deep investigation on the M-S-H structure, and it will be the object of our future research.

Supplementary Materials: The following are available online at https:/ /www.mdpi.com/article/ 10.3390/app11072968/s1. Figure S1: FT-IR spectra of precipitates samples from $500-4000 \mathrm{~cm}^{-1}$, Figure S2: TEM images of precipitated crystals, Figure S3: Elemental composition of metals in M-S-H measured via EDX, Figure S4: Relative metals content in M-S-H measured via EDX ordered from higher to lower, Figure S5: Relative elements content of Ba contain ing M-S-H ordered from highest 
to lowest Ba content, Figure S6: Comparison of total metal to $(\mathrm{Mg}+$ metal ratio measured via ICP OES and EDX), Figure S7: Relative \% of metal species calculated with Phreeqc, Table S1: Comparison of the average ratio of secondary metal to total metal ( $\mathrm{Mg}+$ secondary metal) measured via ICP-OES and EDX.

Author Contributions: Conceptualization, C.R.-A., and M.R.M.; methodology, C.R.-A., C.D., and M.R.M.; software, C.R.-A., M.R.M., and F.D.L.; validation, C.R.-A., M.R.M., C.D., F.D.L., E.B., and S.V.C.; formal analysis, C.R.-A., M.R.M., F.D.L., and E.B.; investigation, C.R.-A., M.R.M., C.D., and F.D.L.; resources, C.R.-A.; data curation, C.R.-A., M.R.M., C.D., F.D.L., and E.B.; writing-original draft preparation, C.R.-A., M.R.M., C.D., F.D.L., and E.B.; writing-review and editing, C.R.-A., M.R.M., C.D., F.D.L., E.B., and S.V.C.; visualization, C.R.-A., and M.R.M.; supervision, C.R.-A.; project administration, C.R.-A.; funding acquisition, C.R.-A. All authors have read and agreed to the published version of the manuscript.

Funding: German Research Foundation (DFG) Project number: RU 2368/1-1. PI: C. Ruiz-Agudo.

Data Availability Statement: The data presented in this study are available within the article and Supplementary Material.

Acknowledgments: This work was performed with the financial support of the German Research Foundation (DFG). C.R.-A. also thanks the SFB 1214 (project A07) funded by the German Research Foundation (DFG) and the Zukunftskolleg from the University of Konstanz. In addition, we would like to thank the personnel of the "Centro de Instrumentation Científica" (University of Granada) for their support and help with the TEM analyses, especially to Dr. María del Mar Abad Sánchez and Cecilia de la Prada for adapting their TEM sessions in these difficult times.

Conflicts of Interest: The authors declare no conflict of interest.

\section{References}

1. Ji, H.; Huang, W.; Xing, Z.; Zuo, J.; Wang, Z.; Yang, K. Experimental study on removing heavy metals from the municipal solid waste incineration fly ash with the modified electrokinetic remediation device. Sci. Rep. 2019, 9, 8271. [CrossRef] [PubMed]

2. Conner, J.R. Chemical Fixation and Solidification of Hazardous Wastes; Van Nostrand Reinhold: New York, NY, USA, 1990.

3. Glasser, F.P. Fundamental aspects of cement solidification and stabilisation. J. Hazard. Mater. 1997, 52, 151-170. [CrossRef]

4. Conner, J.R.; Hoeffner, S.L. A Critical Review of Stabilization/Solidification Technology. Crit. Rev. Environ. Sci. Technol. 1998, 28, 397-462. [CrossRef]

5. Malviya, R.; Chaudhary, R. Factors affecting hazardous waste solidification/stabilization: A review. J. Hazard. Mater. 2006, 137, 267-276. [CrossRef]

6. Sobiecka, E. Investigating the chemical stabilization of hazardous waste material (fly ash) encapsulated in Portland cement. Int. J. Environ. Sci. Technol. 2013, 10, 1219-1224. [CrossRef]

7. Hyatt, N.C.; Ojovan, M.I. Special Issue: Materials for Nuclear Waste Immobilization. Materials 2019, 12, 3611. [CrossRef]

8. Osmanlioglu, A. Immobilization of radioactive waste by cementation with purified kaolin clay. Waste Manag. 2002, 22, 481-483. [CrossRef]

9. Macphee, D.E.; Glasser, F.P. Immobilization Science of Cement Systems. MRS Bull. 1993, 18, 66-71. [CrossRef]

10. Wang, C.; Li, J.; Sun, X.; Wang, L.; Sun, X. Evaluation of zeolites synthesized from fly ash as potential adsorbents for wastewater containing heavy metals. J. Environ. Sci. 2009, 21, 127-136. [CrossRef]

11. Gitari, W.M.; Key, D.L.; Petrik, L.F.; Okujeni, C. Partitioning of major and trace inorganic contaminants in fly ash acid mine drainage derived solid residues. Int. J. Environ. Sci. Technol. 2010, 7, 519-534. [CrossRef]

12. Wu, K.; Shi, H.; de Schutter, G.; Guo, X.; Ye, G. Preparation of alinite cement from municipal solid waste incineration fly ash. Cem. Concr. Compos. 2012, 34, 322-327. [CrossRef]

13. Ojovan, M.I. (Ed.) Handbook of Advanced Radioactive Waste Conditioning Technologies: Woodhead Publishing Series in Energy; Woodhead Publishing: Cambridge, UK, 2011.

14. Glasser, F. Application of inorganic cements to the conditioning and immobilisation of radioactive wastes. In Handbook of Advanced Radioactive Waste Conditioning Technologies: Woodhead Publishing Series in Energy; Ojovan, M.I., Ed.; Woodhead Publishing: Cambridge, UK, 2011; pp. 67-135.

15. Soundararajan, R. An overview of present day immobilization technologies. J. Hazard. Mater. 1990, 24, 199-212. [CrossRef]

16. Myers, T.E.; Zappi, M.E. Laboratory Evaluation of Stabilization/Solidification Technology for Reducing the Mobility of Heavy Metals in New Bedford Harbor Superfund Site Sediment. In Stabilization and Solidification of Hazardous, Radioactive, and Mixed Wastes: 2nd Volume; Gilliam, T.M., Wiles, C.C., Eds.; ASTM International: West Conshohocken, PA, USA, 1992; pp. 304-319.

17. Colangelo, F.; Cioffi, R.; Montagnaro, F.; Santoro, L. Soluble salt removal from MSWI fly ash and its stabilization for safer disposal and recovery as road basement material. Waste Manag. 2012, 32, 1179-1185. [CrossRef] [PubMed] 
18. Yousuf, M.; Mollah, A.; Vempati, R.K.; Lin, T.-C.; Cocke, D.L. The interfacial chemistry of solidification/stabilization of metals in cement and pozzolanic material systems. Waste Manag. 1995, 15, 137-148. [CrossRef]

19. Pandey, V.C.; Singh, N. Impact of fly ash incorporation in soil systems. Agric. Ecosyst. Environ. 2010, 136, 16-27. [CrossRef]

20. Zhang, T.; Vandeperre, L.J.; Cheeseman, C.R. Magnesium-silicate-hydrate cements for encapsulating problematic aluminium containing wastes. J. Sustain. Cem. Based Mater. 2012, 1, 34-45. [CrossRef]

21. Taylor, H. Cement Chemistry; Thomas Telford Publishing: London, UK, 1997.

22. Dupuis, R.; Dolado, J.S.; Surga, J.; Ayuela, A. Doping as a Way to Protect Silicate Chains in Calcium Silicate Hydrates. ACS Sustain. Chem. Eng. 2018, 6, 15015-15021. [CrossRef]

23. Mo, L.; Deng, M.; Tang, M.; Al-Tabbaa, A. MgO expansive cement and concrete in China: Past, present and future. Cem. Concr. Res. 2014, 57, 1-12. [CrossRef]

24. Brew, D.; Glasser, F.P. Synthesis and characterisation of magnesium silicate hydrate gels. Cem. Concr. Res. 2005, 35, 85-98. [CrossRef]

25. Lothenbach, B.; Nied, D.; L'Hôpital, E.; Achiedo, G.; Dauzères, A. Magnesium and calcium silicate hydrates. Cem. Concr. Res. 2015, 77, 60-68. [CrossRef]

26. Roosz, C.; Grangeon, S.; Blanc, P.; Montouillout, V.; Lothenbach, B.; Henocq, P.; Giffaut, E.; Vieillard, P.; Gaboreau, S. Crystal structure of magnesium silicate hydrates (M-S-H): The relation with 2:1 Mg-Si phyllosilicates. Cem. Concr. Res. 2015, 73, 228-237. [CrossRef]

27. Nied, D.; Enemark-Rasmussen, K.; L'Hopital, E.; Skibsted, J.; Lothenbach, B. Properties of magnesium silicate hydrates (M-S-H). Cem. Concr. Res. 2016, 79, 323-332. [CrossRef]

28. Bernard, E.; Lothenbach, B.; Rentsch, D.; Pochard, I.; Dauzères, A. Formation of magnesium silicate hydrates (M-S-H). Phys. Chem. EarthParts A/B/C 2017, 99, 142-157. [CrossRef]

29. Zhang, T.; Cheeseman, C.R.; Vandeperre, L.J. Development of low pH cement systems forming magnesium silicate hydrate (M-S-H). Cem. Concr. Res. 2011, 41, 439-442. [CrossRef]

30. Zhang, T.; Zou, J.; Wang, B.; Wu, Z.; Jia, Y.; Cheeseman, C.R. Characterization of Magnesium Silicate Hydrate (MSH) Gel Formed by Reacting $\mathrm{MgO}$ and Silica Fume. Materials 2018, 11, 909. [CrossRef] [PubMed]

31. Pantazopoulou, E.; Ntinoudi, E.; Zouboulis, A.I.; Mitrakas, M.; Yiannoulakis, H.; Zampetakis, T. Heavy metal stabilization of industrial solid wastes using low-grade magnesia, Portland and magnesia cements. J. Mater. Cycles Waste Manag. 2020, 22, 975-985. [CrossRef]

32. De Ruiter, L.; Austrheim, H. Formation of magnesium silicate hydrate cement in nature. J. Geol. Soc. 2018, 175, 308. [CrossRef]

33. De Ruiter, L.; Gunnæs, A.E.; Dysthe, D.K.; Austrheim, H. Quartz dissolution associated with magnesium silicate hydrate cement precipitation. Solid Earth 2021, 12, 389-404.

34. Dauzeres, A.; Achiedo, G.; Nied, D.; Bernard, E.; Alahrache, S.; Lothenbach, B. Magnesium perturbation in low-pH concretes placed in clayey environment-solid characterizations and modeling. Cem. Concr. Res. 2016, 79, 137-150. [CrossRef]

35. Cole, W.F.; Demediuk, T. X-ray, thermal, and Dehydration studies on Magnesium oxychlorides. Aust. J. Chem. 1955, 8, 234-251. [CrossRef]

36. Sevim, A.M.; Hojiyev, R.; Gül, A.; Çelik, M.S. An investigation of the kinetics and thermodynamics of the adsorption of a cationic cobalt porphyrazine onto sepiolite. Dye. Pigment. 2011, 88, 25-38. [CrossRef]

37. Alexandre-Franco, M.; Albarrán-Liso, A.; Gómez-Serrano, V. An identification study of vermiculites and micas: Adsorption of metal ions in aqueous solution. Fuel Process. Technol. 2011, 92, 200-205. [CrossRef]

38. Walling, S.A.; Kinoshita, H.; Bernal, S.A.; Collier, N.C.; Provis, J.L. Structure and properties of binder gels formed in the system $\mathrm{Mg}(\mathrm{OH})_{2}-\mathrm{SiO}_{2}-\mathrm{H}_{2} \mathrm{O}$ for immobilisation of Magnox sludge. Dalton Trans. 2015, 44, 8126-8137. [CrossRef]

39. Bernard, E.; Lothenbach, B.; Pochard, I.; Cau-Dit-Coumes, C. Alkali binding by magnesium silicate hydrates. J. Am. Ceram. Soc. 2019, 102, 6322-6336. [CrossRef]

40. Zhang, T.; Zou, J.; Li, Y.; Jia, Y.; Cheeseman, C.R. Stabilization/solidification of strontium using magnesium silicate hydrate cement. Processes 2020, 8, 163. [CrossRef]

41. Zhang, T.; Li, T.; Zou, J.; Li, Y.; Zhi, S.; Jia, Y.; Cheeseman, C. Immobilization of radionuclide 133cs by magnesium silicate hydrate cement. Materials 2020, 13, 146. [CrossRef]

42. Parkhurst, D.L.; Appelo, C. (Eds.) Description of Input and Examples for PHREEQC Version 3: A Computer Program for Speciation, Batch-Reaction, One-Dimensional Transport, and Inverse Geochemical Calculations; U.S. Geological Survey: Reston, VA, USA, 2013.

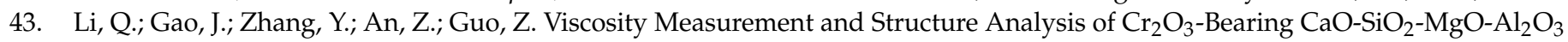
Slags. Metall. Mater. Trans. B 2017, 48, 346-356. [CrossRef]

44. Hou, D.; Ma, H.; Zhu, Y.; Li, Z. Calcium silicate hydrate from dry to saturated state: Structure, dynamics and mechanical properties. Acta Mater. 2014, 67, 81-94. [CrossRef]

45. Bernard, E.; Lothenbach, B.; Chlique, C.; Wyrzykowski, M.; Dauzères, A.; Pochard, I.; Cau-Dit-Coumes, C. Characterization of magnesium silicate hydrate (M-S-H). Cem. Concr. Res. 2019, 116, 309-330. [CrossRef]

46. de Villiers, J.P.R. Crystal Structures of Aragonite, Strontianite, and Witherite. Am. Mineral. 1971, 56, 758-767.

47. de Velasco Maldonado, P.S.; Hernández-Montoya, V.; Concheso, A.; Montes-Morán, M.A. Formation of cerussite and hydrocerussite during adsorption of lead from aqueous solution on oxidized carbons by cold oxygen plasma. Appl. Surf. Sci. 2016, 386, 381-388. [CrossRef] 
48. Temuujin, J.; Okada, K.; MacKenzie, K.J.D. Formation of Layered Magnesium Silicate during the Aging of Magnesium HydroxideSilica Mixtures. J. Am. Ceram. Soc. 1998, 81, 754-756. [CrossRef]

49. Lothenbach, B.; Durdzinski, P.; DeWeerdt, K. Thermogravimetric analysis. In A Practical Guide to Microstructural Analysis of Cementitious Materials; Scrivener, K., Snellings, R., Lothenbach, B., Eds.; CRC Press: Oxford, UK, 2016; pp. 177-212.

50. Cuesta, A.; Ichikawa, R.U.; Londono-Zuluaga, D.; de La Torre, A.G.; Santacruz, I.; Turrillas, X.; Aranda, M.A. Aluminum hydroxide gel characterization within a calcium aluminate cement paste by combined Pair Distribution Function and Rietveld analyses. Cem. Concr. Res. 2017, 96,1-12. [CrossRef]

51. Chiang, W.-S.; Ferraro, G.; Fratini, E.; Ridi, F.; Yeh, Y.-Q.; Jeng, U.-S.; Chen, S.-H.; Baglioni, P. Multiscale structure of calcium- and magnesium-silicate-hydrate gels. J. Mater. Chem. A 2014, 2, 12991-12998. [CrossRef]

52. Wang, Y.; Wang, G.; Wang, H.; Liang, C.; Cai, W.; Zhang, L. Chemical-Template Synthesis of Micro/Nanoscale Magnesium Silicate Hollow Spheres for Waste-Water Treatment. Chem. A Eur. J. 2010, 16, 3497-3503. [CrossRef] [PubMed]

53. Wang, W.; Chen, Z.; Zhou, H.; Zhang, Y.; Wang, X. Two-dimensional lamellar magnesium silicate with large spacing as an excellent adsorbent for uranium immobilization. Environ. Sci. Nano 2018, 5, 2406-2414. [CrossRef]

54. Bernard, E.; Lothenbach, B.; Cau-Dit-Coumes, C.; Pochard, I.; Rentsch, D. Aluminum incorporation into magnesium silicate hydrate (M-S-H). Cem. Concr. Res. 2020, 128, 105931. [CrossRef]

55. Busenberg, E.; Plummer, L.; Parker, V.B. The solubility of strontianite $\left(\mathrm{SrCO}_{3}\right)$ in $\mathrm{CO}_{2}-\mathrm{H}_{2} \mathrm{O}$ solutions between 2 and $91{ }^{\circ} \mathrm{C}$, the association constants of $\mathrm{SrHCO}_{3}{ }_{3}(\mathrm{aq})$ and $\mathrm{SrCO}_{3}{ }_{3}(\mathrm{aq})$ between 5 and $80{ }^{\circ} \mathrm{C}$, and an evaluation of the thermodynamic properties of $\mathrm{Sr}^{2+}(\mathrm{aq})$ and $\mathrm{SrCO}_{3}(\mathrm{cr})$ at $25^{\circ} \mathrm{C}$ and $1 \mathrm{~atm}$ total pressure. Geochim. Cosmochim. Acta 1984, 48, 2021-2035.

56. Tonelli, M.; Martini, F.; Calucci, L.; Fratini, E.; Geppi, M.; Ridi, F.; Borsacchi, S.; Baglioni, P. Structural characterization of magnesium silicate hydrate: Towards the design of eco-sustainable cements. Dalton Trans. 2016, 45, 3294-3304. [CrossRef]

57. Bernard, E.; Lothenbach, B.; Rentsch, D. Influence of sodium nitrate on the phases formed in the $\mathrm{MgO}_{3}-\mathrm{Al}_{2} \mathrm{O}_{3}-\mathrm{SiO}_{2}-\mathrm{H}_{2} \mathrm{O}$ system. Mater. Des. 2021, 198, 109391. [CrossRef] 